\title{
Glycopeptides of Immunoglobulins
}

\author{
INVESTIGATIONS ON IgA MYELOMA GLOBULINS
}

\author{
By J. R. CLAMP AND F. W. PUTNAM* \\ Department of Medicine, University of Bristol, Bristol Royal Infirmary, Bristol 2, and \\ Department of Biochemistry, College of Medicine, University of Florida, \\ Gainesville, Fla., U.S.A.
}

(Received 29 July 1966)

\begin{abstract}
The oligosaccharide units of a type $\mathrm{K}$ and a type $\mathrm{L} \operatorname{IgA}$ immunoglobulin have been examined. The two proteins differed in their content of 6-deoxy-L-galactose and $\mathrm{N}$-acetylneuraminic acid, and in the D-mannose/D-galactose ratio. With glycopeptides prepared from the type $\mathrm{K}$ protein, specific glycosidases liberated the $N$-acetylneuraminic acid and 7-8 residues of 2-acetamido-2-deoxy-D-glucose, and mild acid hydrolysis released most of the 6-deoxy-L-galactose. The type K immunoglobulin appeared to contain 3 oligosaccharide units, whereas the type L protein probably contained 3 or more units.
\end{abstract}

Antibody activity in human serum is associated with a group of related proteins called the immunoglobulins (Heremans, 1959). These consist of three principal classes of proteins, containing different amounts of carbohydrate (Winzler, 1960). Each class can be further divided into two antigenic types, $\mathrm{K}$ and $\mathrm{L}$ (Korngold \& Lipari, 1956), and into various subclasses (Migita \& Putnam, 1963; Terry \& Fahey, 1964). In addition, there is evidence (Fahey, 1959; Fahey \& Horbett, 1959; Franklin, 1962; Clamp \& Putnam, 1964) that the carbohydrate content may vary within a class of immunoglobulins. These various indications of heterogeneity invalidate definitive structural studies on glycopeptides from normal immunoglobulins. However, certain neoplastic disorders, e.g. multiple myeloma, may be associated with the presence in the blood of a homogeneous immunoglobulin. Studies on the oligosaccharide units of such proteins may help in understanding the structure of the immunoglobulins. In addition, studies on myeloma globulins with differing contents of carbohydrate may provide insight into any similarities of structure existing among the oligosaccharide units of immunoglobulins.

\section{METHODS}

Isolation of myeloma globulins. The IgA globulins (nomenclature recommended by the World Health Organisation, 1964) were isolated from the sera of patients with multiple myeloma by a combination of salt fractionation

\footnotetext{
* Present address: Division of Biological Sciences, Indiana University, Bloomington, Ind., U.S.A.
}

and chromatography on DEAE-cellulose. The type $K$ globulin is the specimen previously referred to as $\mathrm{La}$ and the type L as Ha (Bernier, Tominaga, Easley \& Putnam, 1965). The proteins were checked for homogeneity by starch-gel electrophoresis and immunoelectrophoresis, and the class and type of protein determined by immunodiffusion with specific antisera (Migita \& Putnam, 1963).

Preparation of glycopeptides. The type K IgA globulin $\left(0.86 \mathrm{~g}\right.$.), in $0.02 \mathrm{M}^{-\mathrm{CaCl}_{2}}(25 \mathrm{ml}$.) adjusted to $\mathrm{pH} 8.5$ with $\mathrm{N}-\mathrm{NaOH}$, was incubated with $20 \mathrm{mg}$. of Pronase (B grade; California Corp. for Biochemical Research, Los Angeles, Calif., U.S.A.) at $37^{\circ}$ for $48 \mathrm{hr}$. in the presence of thymol and toluene. The solution was then neutralized with $\mathrm{N}-\mathrm{HCl}$, filtered and evaporated to dryness under reduced pressure. The dried material was triturated with ethanol and the residue, after filtration, extracted with water $(3 \times 5 \mathrm{ml}$.). The combined aqueous extracts were passed through a column (125 cm. $\times 2.25 \mathrm{~cm}$. diam.) of Sephadex G-25 (medium grade) (Pharmacia, Uppsala, Sweden) and the carbohydrate-containing fractions (Molisch test) were pooled and evaporated to dryness. A final purification was achieved by descending chromatography on prewashed Whatman 3MM filter paper $(57 \mathrm{~cm} . \times 46 \mathrm{~cm}$.; $25 \mathrm{mg}$./chromatogram) in butan-1-ol-acetic acid-water $(12: 3: 5$, by vol.) for $24 \mathrm{hr}$. The base-line material was eluted from the dried chromatogram with water, filtered through glass wool and evaporated to dryness (yield, approx. $18 \mathrm{mg}$.). The overall recovery of hexose during the preparation of the glycopeptide was $95 \%$.

Glycopeptides were prepared from the type $\mathrm{L} \operatorname{IgA}$ globulin (specimen $\mathrm{Ha}$ ) that had been subjected to treatment with mercaptoethanol, papain digestion and chromatography on Sephadex G-200 (Bernier et al. 1965). The main hexose-containing fraction $(60 \mathrm{mg}$.) eluted from Sephadex G-200 (tubes 100-118; Fig. 1) was hydrolysed with Pronase (2mg.) in $0.02 \mathrm{M}-\mathrm{CaCl}_{2}, \mathrm{pH} 8.5(1 \mathrm{ml}$.), and the glycopeptides were isolated by the method described above (yield, $30 \mathrm{mg}$; overall recovery of hexose, approx. 50-60\%).

Bioch. 1967, 103 


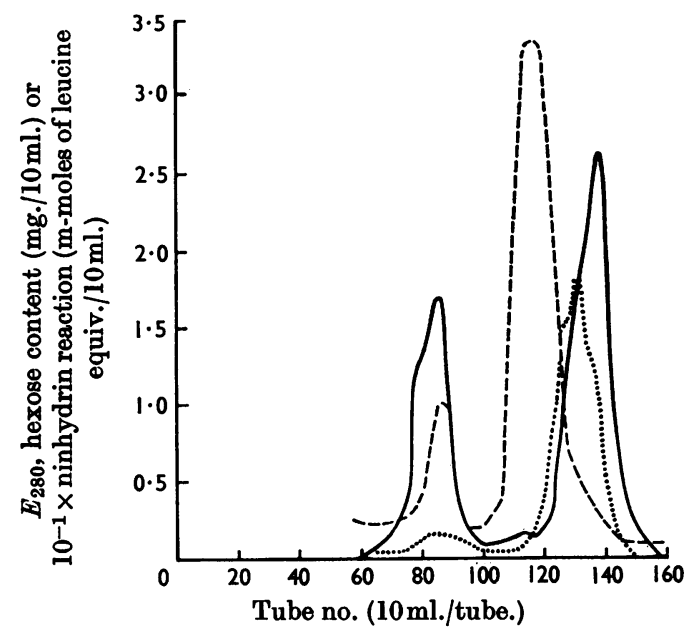

Fig. 1. Chromatography on Sephadex G-200 of a papain digest of mercaptoethanol-treated IgA type L immunoglobulin. The eluent was $0 \cdot 1 \mathrm{~m}$-sodium phosphate buffer, pH6.0. - $E_{280}$; ----, hexose content (phenol- $\mathrm{H}_{2} \mathrm{SO}_{4}$ method); ......., ninhydrin reaction (leucine equivalents). The first hexose-containing peak consisted largely of undegraded immunoglobulin.

Paper chromatography. The chromatography of carbohydrates and amino acids was carried out as described previously (Clamp \& Putnam, 1964; Clamp \& Hough, 1965). Peptides were separated on Whatman 3MM filter paper by a two-dimensional technique (Putnam, Migita \& Easley, 1962).

Analytical procedures. For each carbohydrate estimation a calibration curve was prepared by using a solution of the monosaccharides in the same molar proportions as in the original glycoprotein. Interference by protein in the colorimetric procedures was allowed for as described previously (Clamp \& Putnam, 1964). For estimations on the glycopeptide material, the standard solution contained in addition the equivalent amounts of amino acids found by the analytical procedures described below.

Hexoses were determined by the phenol- $\mathrm{H}_{2} \mathrm{SO}_{4}$ method (Dubois, Gilles, Hamilton, Rebers \& Smith, 1956) and by a modification (Clamp\& Putnam, 1964) of the orcinol method (Vasseur, 1948). 6-Deoxy-L-galactose was estimated by the cysteine method (Dische \& Shettles, 1948). Free $N$-acetylneuraminic acid was determined by the thiobarbituric acid method (Warren, 1959) and the combined acid by the resorcinol procedure (Svennerholm, 1957). 2-Amino-2deoxy-D-glucose was assayed by a modification (Boas, 1953) of the Elson \& Morgan (1933) method after preliminary hydrolysis of the sample in $2 \mathrm{~N}-\mathrm{HCl}$ at $98-100^{\circ}$ for $6 \mathrm{hr}$. and subsequent neutralization with $2 \mathrm{~N}-\mathrm{NaOH}$. 2-Acetamido-2deoxy-D-glucose was estimated by the method of Morgan \& Elson (1934). Carbohydrates were also assayed by gasliquid chromatography (Bolton, Clamp \& Hough, 1965; Bolton, Clamp, Dawson \& Hough, 1965). Amino acids were determined (Moore, Spackman \& Stein, 1958) with the Beckman Spinco model MS amino acid analyser, after hydrolysis of the glycopeptide in $6 \mathrm{~N}-\mathrm{HCl}$ at $105^{\circ}$ for $22 \mathrm{hr}$.
Peptides in the effluent after column chromatography were detected by a similar ninhydrin reaction (Moore \& Stein, 1954) and expressed in leucine equivalents.

The D-mannose/D-galactose ratio was determined both by the method of paper chromatography after resin hydrolysis (Clamp \& Putnam, 1964) and by the technique of gas-liquid chromatography.

Chemical examination of end groups. The glycopeptides were shown to be non-reducing by the absence of a glycitol after treatment of the glycopeptide with $\mathrm{NaBH}_{4}$, hydrolysis and alkaline destruction of the reducing sugars (Clamp \& Hough, 1965).

The glycopeptides were also hydrolysed with $0.75 \mathrm{~N}-\mathrm{HC}$ at $100^{\circ}$; samples were removed at intervals, placed in a vacuum desiccator at $4^{\circ}$ over $\mathrm{NaOH}$ pellets and $\mathrm{P}_{2} \mathrm{O}_{5}$ and, when dry, were examined by gas-liquid chromatography.

Enzymic hydrolyses. In each glycosidase experiment, the liberated monosaccharide was estimated by using a standard curve constructed from a solution of the sugar in the appropriate enzyme mixture. Enzymic hydrolyses were carried out at $37^{\circ}$ and samples of the enzymic digests were examined at intervals by paper chromatography to monitor the monosaccharide liberation; one monosaccharide only was detected in each case.

A preparation of 2 -acetamido-2-deoxy- $\beta$-D-glucosidase ( $\beta$ - $N$-acetylglucosaminidase) free from other glycosidase activity, that had been isolated from boar epididymis and kindly supplied by Dr G. A. Levvy, was made up in 0.1 M$\mathrm{NaCl}$ containing bovine serum albumin $(0 \cdot 1 \%)$ and the $\mathrm{pH}$ adjusted to 4.5 with $0.1 \mathrm{~N}-\mathrm{HCl}$. The glycopeptide (4.7 mg.) from the type $\mathrm{K}$ IgA globulin was added to this enzyme solution (5 ml.) and samples $(0.25 \mathrm{ml}$.) were withdrawn at intervals for estimation of the liberated 2-acetamido-2deoxy-D-glucose.

Neuraminidase solution (General Biochemicals Inc., Chagrin Falls, Ohio, U.S.A.) (0.5 ml.) was added to a solution of the glycopeptide $(5.0 \mathrm{mg}$.) in $0.05 \mathrm{~m}$-acetate buffer, pH5.5 (10 ml.). Samples (1.0 ml.) were taken at intervals and the liberated $N$-acetylneuraminic acid was determined by the thiobarbituric acid technique. At the end of the incubation period, the solution was evaporated to a small volume and passed through a column $(40 \mathrm{~cm} . \times 2 \mathrm{~cm}$. diam.) of Sephadex G-25 (fine grade). The carbohydrate-containing fractions were pooled, concentrated and subjected to twodimensional chromatography.

Molecular-weight determination. Sedimentation-velocity and diffusion measurements on the type K IgA globulin glycopeptide were kindly performed by Dr J. J. Cebra, Department of Microbiology, University of Florida, by using a synthetic-boundary cell in a Spinco model E ultracentrifuge. The conditions of the experiment and the calculations were as described previously (Clamp \& Putnam, 1964).

\section{RESULTS}

Estimations of the carbohydrate contents of a type $\mathrm{K}$ IgA globulin and a type L IgA globulin are given in Table 1. Within the limits of experimental error the two proteins appear to contain similar amounts of total hexose and aminohexose, but to differ in their contents of 6-deoxy-L-galactose and $N$-acetylneuraminic acid and in the D-mannose/Dgalactose ratio. 
Table 1. Carbohydrate content of IgA globulins and glycopeptides

Experimental details are given in the text.

Carbohydrate content (g./100g.)

Monosaccharide

6-Deoxy-L-galactose

D-Mannose

D-Galactose

D-Mannose/D-galactose ratio

Total hexose

2-Amino-2-deoxy-D-glucose

$N$-Acetylneuraminic acid
Method of estimation

Colorimetric

Gas-liquid chromatography Colorimetric

Gas-liquid chromatography Colorimetric

Gas-liquid chromatography

Gas-liquid chromatography Colorimetric

Gas-liquid chromatography Colorimetric

Gas-liquid chromatography Colorimetric

Gas-liquid chromatography

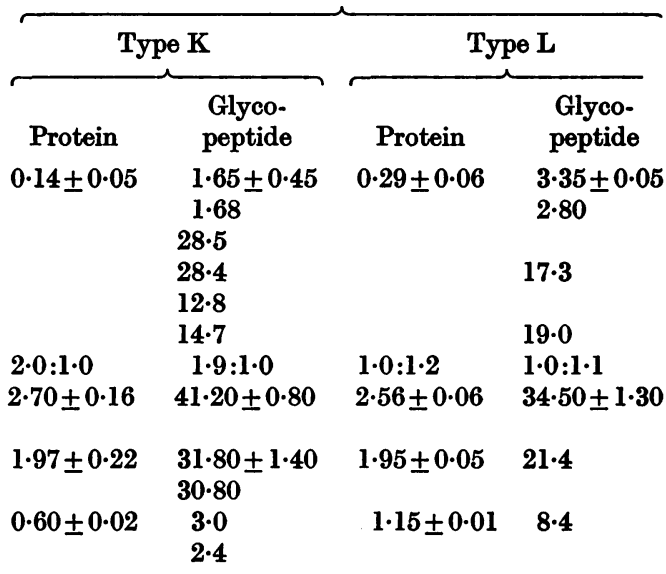

Table 2. Amino acid composition of the glycopeptides

Details are given in the text. The results are given relative to the aspartic acid value. Amino acids present in a molar proportion of less than 0.05 are not included.

\begin{tabular}{lcc} 
& \multicolumn{2}{c}{ Molar proportion } \\
\cline { 2 - 3 } & Type K & Type L \\
Aspartic acid & 1.00 & 1.00 \\
Threonine & 0.20 & 0.34 \\
Serine & 0.45 & 0.48 \\
Glutamic acid & 0.45 & 0.18 \\
Proline & 0.42 & 0.57 \\
Glycine & 0.33 & 0.06 \\
Alanine & 0.40 & 0.42 \\
Cystine (half) & 0.17 & - \\
Valine & 0.38 & 0.36
\end{tabular}

Two-dimensional peptide 'maps' of the two proteins were made as in the work of Bernier et al. (1965). With the type $\mathrm{K}$ protein two glycopeptides $\left(F_{1}\right.$ and $\left.F_{2}\right)$ were found by periodate-silver nitrate staining. The glycopeptides did not move during chromatography in butanol-acetic acid-water, but were separated by electrophoresis : glycopeptide $\mathbf{F}_{2}$ moved somewhat further towards the cathode than did glycopeptide $F_{1}$. The two glycopeptides were separated by high-voltage electrophoresis on Whatman 3MM filter paper (Clamp \& Putnam, 1964), and after elution were found to differ in their content of sialic acid since only glycopeptide $F_{1}$ contained this monosaccharide. This accords with the greater cathodic mobility of glycopeptide $\mathbf{F}_{2}$. Three glycopeptides were found in the type $\mathrm{L}$ protein, two of which had mobilities corresponding to glycopeptides $F_{1}$ and $F_{2}$ of the type $K$ protein whereas the third glycopeptide spot had a greater anodic mobility than glycopeptide $F_{1}$. The remainder of the studies were carried out on glycopeptides that had not been separated into the above fractions.

The carbohydrate contents of the glycopeptides prepared from the two proteins are given in Table 1 and the amino acid compositions are shown in Table 2. Amino acid analysis of $0.5 \mathrm{mg}$. of the glycopeptide from the type $K$ protein yielded $0.15 \mu$ mole of aspartic acid, whereas $1.56 \mathrm{mg}$. of the glycopeptide from the type L protein gave 0.39 $\mu$ mole of aspartic acid. These values correspond to equivalent weights of 3300 and 4000 respectively, in terms of the aspartic acid content. The glycopeptide from the type $\mathrm{K}$ immunoglobulin had sedimentation and diffusion coefficients of $0.724 \mathrm{~s}$ and 25.4 Fick units respectively, which correspond to a molecular weight of 2800 .

The molar proportions of monosaccharide residues appear to be similar in both the glycopeptide and the corresponding immunoglobulin (Table 3) with the exception of sialic acid, which has a labile glycosidic linkage and may be lost during the isolation procedures (Clamp \& Putnam, 1964).

All the sialic acid was liberated by neuraminidase from the type $K$ immunoglobulin glycopeptide within $48 \mathrm{hr}$., and at the end of this time the twodimensional peptide 'map' showed only the presence of the $F_{2}$ glycopeptide. 2-Acetamido-2-deoxy- $\beta$-Dglucosidase caused the release of acetamidohexose from the type $\mathrm{K}$ immunoglobulin glycopeptide, as shown in Fig. 2. After $142 \mathrm{hr}$. approx. $40 \%$ of the 
Table 3. Carbohydrate composition of immunoglobulins and glycopeptides

The carbohydrate contents of the two IgA immunoglobulins are compared with those of the corresponding glycopeptides, the results being expressed to the nearest whole residue. The proportion of $N$-acetylneuraminic acid is lower in the glycopeptides owing to losses during the isolation procedures (Clamp \& Putnam, 1964). Experimental details are given in the text.

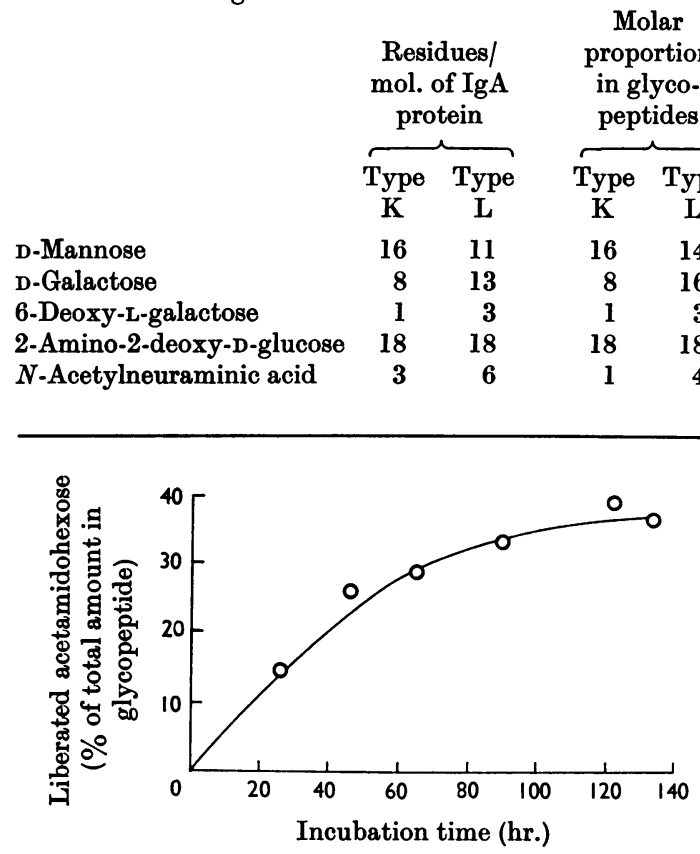

Fig. 2. Liberation of 2-acetamido-2-deoxy-D-glucose from the type K IgA immunoglobulin glycopeptide (0.94 mg. $/ \mathrm{ml}$.) by an enzyme preparation from boar epididymis (1000 units/ml.). Experimental details are given in the text.

total acetamidohexose had been liberated and this corresponds to 7-8 residues. Acid hydrolysis $(0.75 \mathrm{~N}$-hydrochloric acid) liberated $87 \%$ of the total 6-deoxy-L-galactose before the appearance of small amounts of $\mathbf{D}$-galactose.

\section{DISCUSSION}

The type $K$ and $L$ immunoglobulins are differentiated on the basis of the serological specificities of their light chains and this differentiation does not depend on any difference in their carbohydrate moieties.

The points of interest in the investigation of the oligosaccharide units of immunoglobulins include the site of the glycopeptides within the protein molecule, the mode of attachment between carbohydrate and peptide, the number of oligosaccharide units in the protein and the structure of the carbohydrate moiety. Determination of the number of oligosaccharide units in the protein molecule provides the most useful information for correlation with the overall immunoglobulin structure. In order to estimate the number of oligosaccharide units in a glycoprotein the carbohydrate content of the original protein and of the isolated glycopeptides must be accurately determined. The glycopeptide must be prepared by a method that cleaves most of the peptide linkages, to obviate any difficulties that would arise if two oligosaccharide units were attached to a length of peptide chain that remained intact. During the isolation of the glycopeptides, the overall yield of carbohydrate material must be high, and as an additional check the ratio of monosaccharide units in the glycopeptide must be the same as in the original protein. Finally, the molecular weights of the protein and glycopeptide material must be determined.

The molecular weights and sedimentation coefficients of IgA globulin monomers are about 150000-160000 and $7 \mathrm{~s}$ respectively (Levin, Ritzmann, Seeuwen \& Nanninga, 1964; Press \& Porter, 1966), and the values established for the type $\mathrm{K} \& \mathrm{~L}$ proteins were in agreement with these values (Bernier et al. 1965). Since myeloma globulins formed the basis of this study, the amount of protein available was limited, and therefore any procedure that gave an indication of the size or the number of oligosaccharide units was of use in preliminary studies on the protein. The carbohydrate-containing peptides did not move in butan-1-ol-acetic acid-water, but were separated by electrophoresis according to their content of sialic acid. The type $\mathrm{K}$ protein showed only two glycopeptide spots, one of which contained no sialic acid and the other a single residue. Since the immunoglobulin contained 3 residues of $\mathrm{N}$-acetylneuraminic acid, the original protein contained at least 3 oligosaccharide units. An indication of the size of the glycopeptide is provided by the aspartic acid content (Clamp, Dawson \& Putnam, 1965), which corresponded to an equivalent weight for the glycopeptide of 3300 . If all the carbohydrate were divided equally between three glycopeptides, each would have a molecular weight of approx. 3200 . The ratio of aminohexose to aspartic acid in the glycopeptide was $6: 1$, and as there were approx. 18 aminohexose residues in the original protein (Table 3) this again is consistent with the presence of 3 oligosaccharide units. The above methods for indicating the size of the glycopeptides are valuable when the supply of material is too limited for more definitive studies. However, with the type $\mathrm{K}$ protein it was possible to carry out in addition a physicochemical determination of the molecular weight of the glycopeptide and this corresponded to 
2800, thereby supporting the preliminary findings. Within the limits of experimental error this immunoglobulin would therefore seem to contain 3 oligosaccharide units. If the structure of the $\operatorname{IgA}$ molecule is similar to that of IgG, then one of the two heavy chains must contain at least 2 oligosaccharide units. Alternative possibilities are either that there are more than two heavy chains in the protein (Bernier et al. 1965) or that the carbohydrate is associated with a smaller fragment, which is capable of polymerization independently of the main bulk of the heavy chain (Franklin, 1964).

Owing to a limited supply of material, the glycopeptides from the type $\mathrm{L}$ protein were isolated during another experiment and therefore the information is much less complete and more contradictory. The yield of aspartic acid suggests that the glycopeptide has an equivalent weight of 4000 and this would correspond to the presence of 3 oligosaccharide units in the original protein. On the other hand, the 6-deoxy-L-galactose content of the glycopeptide and the aminohexose/aspartic acid ratio $(4 \cdot 5: 1 \cdot 0)$ are more consistent with the presence of 4 oligosaccharide units. There were 3 glycopeptide spots in the two-dimensional peptide 'map' of the type L protein. One of these spots was in a position corresponding to the neutral glycopeptide of IgG (Clamp \& Putnam, 1964) and IgA (glycopeptide $F_{2}$, see above), and another corresponded to the glycopeptide containing a single sialic acid residue (glycopeptide $F_{1}$ ). The third glycopeptide spot was in a position corresponding to a glycopeptide with two sialic acid residues. Since the original protein contained $6 N$-acetylneuraminic acid residues, the peptide 'map' would be consistent with the presence of 3 or more oligosaccharide units.

Although both proteins had similar contents of total hexose and aminohexose, they differed in their contents of 6-deoxy-L-galactose, $N$-acetylneuraminic acid and in the $D$-mannose/D-galactose ratio. The type $\mathrm{K}$ globulin had a $\mathrm{D}$-mannose/D-galactose ratio approx. $2: 1$, whereas in the type $L$ protein the ratio was approx. $1: 1$. These values emphasize the considerable differences that may exist between glycoproteins, even those belonging to the same immunological class.

The type $\mathrm{K}$ globulin may possess as many as 1112 non-reducing end groups consisting of the 6-deoxy-L-galactose and $N$-acetylneuraminic acid, and possibly 7-8 residues of 2-acetamido-2-deoxyD-glucose. In three immunoglobulins that have now been examined in detail (Clamp \& Putnam, 1964; Clamp et al. 1965), the number of acetamidohexose non-reducing end groups has been similar to the total number of $D$-galactose residues in the protein. This may be evidence for the existence of branched chains containing $D$-galactose and terminated by an acetamidohexose residue, as described in the $\alpha_{1}$-acid glycoprotein by Jeanloz (1964).

This work was supported by Research Grant CA-02806 from the National Cancer Institute, National Institutes of Health, U.S. Public Health Service.

\section{REFERENCES}

Bernier, G. M., Tominaga, K., Easley, C. W. \& Putnam, F. W. (1965). Biochemistry, 4, 2072.

Boas, N. F. (1953). J. biol. Chem. 204, 553.

Bolton, C. H., Clamp, J. R., Dawson, G. \& Hough, L. (1965). Carbohyd. Res. 1, 333.

Bolton, C. H., Clamp, J. R. \& Hough, L. (1965). Biochem.J. 96, $5 \mathrm{c}$.

Clamp, J. R., Dawson, G. \& Putnam, F. W. (1965). Biochem. $J .95,22 P$.

Clamp,J. R. \& Hough, L. (1965). Biochem.J. 94, 502.

Clamp, J. R. \& Putnam, F. W. (1964). J. biol. Chem. 239, 3233.

Dische, Z. \& Shettles, L. B. (1948). J. biol. Chem. 175, 595.

Dubois, M., Gilles, K. A., Hamilton, J. K., Rebers, P. A. \& Smith, F. (1956). Analyt. Chem. 28, 350.

Elson, L. A. \& Morgan, W. T. J. (1933). Biochem. J. 27, 1824.

Fahey, J. L. (1959). Fed.Proc.18,43.

Fahey, J. L. \& Horbett, A. P. (1959). J. biol. Chem. 234, 2645.

Franklin, E. C. (1962). Nature, Lond., 195, 392.

Franklin, E. C. (1964). J.exp. Med.120,691.

Heremans, J. F. (1959). Clin. chim. Acta, 4, 639.

Jeanloz, R. W. (1964). Medicine, 43, 363.

Korngold, L. \& Lipari, R. (1956). Cancer, 9, 262.

Levin, W. C., Ritzmann, S. E., Seeuwen, J. P. \& Nanninga, L. (1964). Clin. chim. Acta,10, 12.

Migita, S. \& Putnam, F. W. (1963). J.exp. Med.117, 81.

Moore, S., Spackman, D. H. \& Stein, W. H. (1958). Analyt. Chem. 80, 1185.

Moore, S. \& Stein, W. H. (1954). J.biol.Chem. 211, 907.

Morgan, W. T. J. \& Elson, L. A. (1934). Biochem.J. 28, 988.

Press, E. M. \& Porter, R. R. (1966). In Glycoproteins:Their

Composition, Structure and Function, p. 395. Ed. by Gottschalk, A. Amsterdam: Elsevier Publishing Co.

Putnam, F. W., Migita, S. \& Easley, C. W. (1962). In Protides of the Biological Fluids, vol. 10, p. 93. Ed. by Peeters, H. Amsterdam : Elsevier Publishing Co.

Svennerholm, L. (1957). Biochim. biophys. Acta, 24, 604.

Terry, W. D. \& Fahey, J. L. (1964). Science, 146, 400.

Vasseur, E. (1948). Acta chem. scand.2, 693.

Warren, L. (1959). J.biol. Chem. 234, 1971.

Winzler, R. J. (1960). In The Plasma Proteins, vol. 1, p. 309.

Ed. by Putnam, F. W. New York: Academic Press Inc.

World Health Organisation (1964). Bull. World Hlth Org. 